\title{
Board Certification Characteristics of Practicing Neuroradiologists
}

\author{
(D) A.B. Rosenkrantz, (D) G.N. Nicola, (D).A. Hirsch, and (D) R. Duszak Jr.
}

\begin{abstract}
BACKGROUND AND PURPOSE: Insight into the status of neuroradiology subspecialty certification across the United States could help to understand neuroradiologists' perceived value of subspecialty certification as well as guide efforts to optimize pathways for broader voluntary certification participation. Our aim was to assess board certification characteristics of practicing US neuroradiologists.
\end{abstract}

MATERIALS AND METHODS: The American Board of Radiology public search engine was used to link Medicare-participating radiologists with American Board of Radiology diplomates. Among linked diplomates, 4670 neuroradiologists were identified on the basis of 3 criteria: current or prior neuroradiology subspecialty certification or currently $>50 \%$ clinical work effort in neuroradiology based on work relative value unit-weighted national Medicare claims ("majority-practice neuroradiologists"). Subspecialty certification status was studied in each group, using Centers for Medicare \& Medicaid Services data to identify additional physician characteristics.

RESULTS: Of 3769 included radiologists ever subspecialty certified, 84.1\% are currently subspecialty certified. Of 1777/3769 radiologists ever subspecialty-certified and with lifetime primary certificates (ie, nonmandated Maintenance of Certification), only $66.6 \%$ are currently subspecialty certified. Of 3341 included majority-practice neuroradiologists, $73.0 \%$ were ever subspecialty certified; of these, $89.1 \%$ are currently subspecialty certified. Of 3341 majority-practice neuroradiologists, the fraction currently subspecialty certified was higher for those in academic (81.3\%) versus nonacademic (58.2\%) practices, larger versus smaller practices $(72.1 \%$ for those in $\geq 100$ versus $36.1 \%$ for $<10$-member practices), US regions other than the West $(64.1 \%-70.6 \%$ versus $56.5 \%)$, fewer years in practice $(77.5 \%$ for $11-20$ years versus $31.3 \%$ for $>50$ years), and time-limited $(73.5 \%)$ versus lifetime (54.9\%) primary certificates.

CONCLUSIONS: More than one-quarter of majority-practice neuroradiologists never obtained neuroradiology subspecialty certification. Even when initially obtained, that certification is commonly not maintained, particularly by lifetime primary certificate diplomates and those in nonacademic and smaller practices. Further investigation is warranted to better understand neuroradiologists' decisions regarding attaining and maintaining subspecialty certification.

ABBREVIATIONS: $\mathrm{ABR}=$ American Board of Radiology; $C M S=$ Centers for Medicare \& Medicaid Services; DR = diagnostic radiology; MOC = Maintenance of Certification; IR = interventional radiology

$\mathbf{N}$ euroradiology is one of the few diagnostic radiology subspecialties for which the American Board of Radiology (ABR) offers subspecialty certification. Beginning in 1995, the ABR offered neuroradiologists the opportunity to undergo additional

Received July 15, 2019; accepted after revision August 7.

From the Department of Radiology (A.B.R.), NYU Langone Medical Center, New York, New York; Hackensack Radiology Group, P.A. (G.N.N.), River Edge, New Jersey; Department of Radiology (J.A.H.), Massachusetts General Hospital, Harvard Medical School, Boston, Massachusetts; and Department of Radiology and Imaging Sciences (R.D.), Emory University School of Medicine, Atlanta, Georgia.

Drs. Rosenkrantz, Hirsch, and Duszak are supported by research grants from the Harvey L. Neiman Health Policy Institute.

Please address correspondence to Andrew B. Rosenkrantz, MD, Department of Radiology, NYU Langone Health, 660 First Ave, New York, NY 10016; e-mail: Andrew.Rosenkrantz@nyumc.org; @arosenkrantzmd

http://dx.doi.org/10.3174/ajnr.A6225 advanced testing to receive this certification beyond their primary radiology certificates. ${ }^{1,2}$ The additional certification is intended to demonstrate to the public that such diplomates have attained the knowledge, problem-solving ability, and skills to be capable of working safely and effectively in various sectors of the subspecialty. $^{3}$ Furthermore, subspecialty diplomates are required to engage in periodic cognitive assessment to demonstrate life-long learning and practice improvement. ${ }^{2,4,5}$ The processes for receiving and maintaining neuroradiology subspecialty certification have been described as elevating the nationwide level of neuroradiology practice. ${ }^{2}$

Neuroradiology subspecialty certification (initially designated as a Certificate of Added Qualification) has evolved as part of a broader shift in board certification throughout medicine. 


\begin{tabular}{ll}
\hline \multicolumn{1}{c}{ Term } & Description \\
\hline Currently subspecialty certified & $\begin{array}{c}\text { Attained ABR neuroradiology subspecialty certification, with this subspecialty certificate } \\
\text { currently in MOC } \\
\text { Previously subspecialty certified } \\
\text { Attained ABR neuroradiology subspecialty certification, with this subspecialty certificate } \\
\text { not currently in MOC } \\
\text { Majority-neuroradiology practice }\end{array}$ \\
$\begin{array}{l}\text { Never attained ABR neuroradiology subspecialty certification } \\
\text { Has highest relative work effort in neuroradiology, with this neuroradiology work effort } \\
\text { exceeding } 50 \% \text { on a work relative value unit basis }\end{array}$ \\
\hline
\end{tabular}

Historically, it was achieved after passing an oral examination separate from the oral examination undertaken to obtain primary certification. ${ }^{6}$ Currently, in order to be eligible, radiologists must first obtain primary certification in diagnostic radiology (DR), interventional radiology/diagnostic radiology (IR/DR), or general radiology (a historical primary certificate no longer offered by the ABR). ${ }^{3}$ For eligible diplomates, neuroradiology subspecialty certification entails completing a 1-year accredited neuroradiology fellowship, 1 year of clinical practice (or additional approved training, at least a third of which must be in neuroradiology), and a dedicated computer-based image-rich neuroradiology subspecialty certification examination. ${ }^{7}$ The latter is distinct from the DR or other primary certifying examinations, comprising exclusively modules of advanced-level questions in brain, head and neck, and spine imaging, as well as an additional certification fee. ${ }^{7,8}$ When primary certificates were used to provide lifetime certification, the periodic testing for neuroradiology subspecialty Maintenance of Certification (MOC) represented additional testing that DR and other primary certificate diplomates otherwise were not required to undergo as a condition of the primary certificate. ${ }^{2}$ However, in the current era of time-limited primary certificates and subsequent mandated primary certificate MOC, the MOC processes for the primary DR and neuroradiology subspecialty certificates are integrated into a single MOC program-that is, DR diplomates are able to fulfill the MOC requirements for both certificates by completing the same number of MOC questions as for an individual certificate and paying only a single MOC fee to the ABR. ${ }^{9}$

There are currently few available data regarding the status of neuroradiology subspecialty certification across the United States, including, for example, its overall presence among neuroradiologists as well as the clinical contexts and practice patterns in which it is most common. Such information could be useful for understanding neuroradiologists' perceived value of subspecialty certification as well as guiding effort to optimize pathways for broader voluntary certification participation. We therefore conducted this study to assess board certification characteristics of practicing US neuroradiologists.

\section{MATERIALS AND METHODS}

This retrospective study of publicly available data did not represent human subjects' research and therefore did not require oversight by our institutional review boards.

The 2016 Centers for Medicare \& Medicaid Services (CMS) Physician and Other Supplier: Provider Utilization Public Use File was used to identify US radiologists participating in the
Medicare program. These radiologists were then linked to diplomates certified by the ABR on the basis of data provided by the $A B R$ in its public search engine, consistent with the methodology in an earlier work. ${ }^{10}$ This linkage process was based on identification of the optimal match between radiologists in the separate CMS and ABR datasets, wherein radiologists were excluded when no single unambiguous linkage was identified. For linked radiologists, we extracted information from the ABR search engine to determine awarded ABR certificates, whether such certificates were maintained in the MOC program of the $A B R$, and whether primary certificates had lifetime or time-limited status. A claimsbased system incorporating work relative value unit-weighting that maps imaging families to radiology subspecialties was used to compute each radiologist's percentage of billed work effort in neuroradiology. ${ }^{11-13}$

Radiologists who could be linked between CMS and ABR data sources were then selected for inclusion within this investigation if they met any 3 of the following nonoverlapping criteria: 1) having attained neuroradiology subspecialty certification with this subspecialty certificate currently in MOC (currently subspecialty certified), 2) having attained neuroradiology subspecialty certification with this subspecialty certificate not currently in MOC (previously subspecialty certified), or 3) having never attained neuroradiology subspecialty certification (never subspecialty certified) though having their highest relative work effort in neuroradiology and this neuroradiology work effort exceeding $50 \%$ on a work relative value unit basis (majorityneuroradiology practice). Table 1 summarizes the designations used in these criteria. Additional information for included radiologists was then extracted from both the 2016 Provider Utilization Public Use File and the separate CMS Physician Compare national downloadable file ${ }^{14}$ datasets, including group practice size, medical school graduation year (which was used to estimate years in practice), academic status using practice affiliations provided by CMS, and an academic status classification system. ${ }^{15}$

All included radiologists were summarized in a descriptive fashion, stratified by various combinations of radiologist, certification, and radiology practice characteristics. Multivariable logistic regression was performed to identify factors independently associated with neuroradiology subspecialty certification in MOC among majority-practice neuroradiologists. These rates were also determined at the state level and depicted graphically (USA Heat Map Generator; Someka, Excel Solutions; https://www.someka. net/). The analysis was performed using Excel for Windows (Microsoft; Redmond, Washington) and MedCalc for Windows (MedCalc Software, Mariakerke, Belgium). 
Table 2: Distribution of physician and practice characteristics, stratified by the 3 study inclusion criteria ${ }^{a}$

\begin{tabular}{|c|c|c|c|}
\hline & $\begin{array}{c}\text { Currently } \\
\text { Subspecialty } \\
\text { Certified }\end{array}$ & $\begin{array}{c}\text { Previously } \\
\text { Subspecialty } \\
\text { Certified }\end{array}$ & $\begin{array}{c}\text { Never Subspecialty } \\
\text { Certified, Majority- } \\
\text { Neuroradiology } \\
\text { Practice }\end{array}$ \\
\hline No. & 3168 & 601 & 901 \\
\hline $\begin{array}{c}\text { Mean neuroradiology } \\
\text { work effort }\end{array}$ & $69.0 \%$ & $52.2 \%$ & $72.4 \%$ \\
\hline Academic & $30.0 \%$ & $14.1 \%$ & $15.0 \%$ \\
\hline \multicolumn{4}{|l|}{ Group practice size } \\
\hline$<10$ & $9.6 \%$ & $27.5 \%$ & $19.6 \%$ \\
\hline $10-49$ & $31.9 \%$ & $37.1 \%$ & $29.9 \%$ \\
\hline $50-99$ & $14.4 \%$ & $9.8 \%$ & $13.8 \%$ \\
\hline$\geq 100$ & $44.0 \%$ & $25.6 \%$ & $36.7 \%$ \\
\hline \multicolumn{4}{|l|}{ Region } \\
\hline Midwest & $22.6 \%$ & $17.6 \%$ & $18.5 \%$ \\
\hline Northeast & $24.1 \%$ & $21.6 \%$ & $19.8 \%$ \\
\hline South & $31.2 \%$ & $37.8 \%$ & $31.0 \%$ \\
\hline West & $22.1 \%$ & $23.0 \%$ & $30.7 \%$ \\
\hline \multicolumn{4}{|l|}{ Years in practice } \\
\hline$\leq 10$ & $7.4 \%$ & $0.0 \%$ & $10.4 \%$ \\
\hline $11-20$ & $42.5 \%$ & $1.3 \%$ & $32.8 \%$ \\
\hline $21-30$ & $26.6 \%$ & $24.3 \%$ & $29.5 \%$ \\
\hline $31-40$ & $19.7 \%$ & $53.2 \%$ & $19.8 \%$ \\
\hline $41-50$ & $3.4 \%$ & $17.5 \%$ & $6.1 \%$ \\
\hline$\geq 51$ & $0.4 \%$ & $3.6 \%$ & $1.3 \%$ \\
\hline \multicolumn{4}{|l|}{ Primary certificate } \\
\hline Lifetime & $37.4 \%$ & $98.7 \%$ & $46.4 \%$ \\
\hline Time-limited & $62.6 \%$ & $1.3 \%$ & $53.6 \%$ \\
\hline
\end{tabular}

${ }^{a}$ Cells in columns for given characteristics add up to $100 \%$.

\section{RESULTS}

The final cohort consisted of 4670 radiologists linked between CMS and ABR datasets and who met further inclusion criteria. This cohort included 3168 currently subspecialty-certified neuroradiologists, 601 previously subspecialty-certified neuroradiologists, and 901 never subspecialty-certified radiologists with majority-neuroradiology practices. Included radiologists' primary certificates were DR in 4510 , IR/DR in 125 , and general radiology in 35 .

A total of $84.1 \%(3168 / 3769)$ of radiologists with neuroradiology subspecialty certification were currently subspecialty certified. Among the 3769 included radiologists having ever attained neuroradiology subspecialty certification, 1777 had a lifetime primary certificate. Among these, 1184 (66.6\%) were currently subspecialty certified. Among the 3769 who ever attained neuroradiology subspecialty certification, 1992 had a time-limited primary certificate. Among these, 1984 (99.6\%) were currently subspecialty certified. Among 3341 included radiologists with majority-neuroradiology practices, 2440 (73.0\%) had ever obtained neuroradiology subspecialty certification; and of these, 2175 (89.1\%) were currently subspecialty certified.

Table 2 summarizes the distribution of physician and practice characteristics based on the 3 separate inclusion criteria of the study. The mean neuroradiology work effort was $69.0 \%$ for those currently

Table 3: Distribution of physician and practice characteristics, stratified by combinations of primary certificate status and neuroradiology subspecialty certification status ${ }^{a}$

\begin{tabular}{|c|c|c|c|c|c|}
\hline & $\begin{array}{l}\text { Lifetime Primary; } \\
\text { Currently } \\
\text { Subspecialty } \\
\text { Certified }\end{array}$ & $\begin{array}{l}\text { Lifetime Primary; } \\
\text { Previously } \\
\text { Subspecialty } \\
\text { Certified }\end{array}$ & $\begin{array}{l}\text { Lifetime } \\
\text { Primary; Never } \\
\text { Subspecialty } \\
\text { Certified } \\
\end{array}$ & $\begin{array}{c}\text { Time-Limited } \\
\text { Primary; Currently } \\
\text { Subspecialty } \\
\text { Certified }\end{array}$ & $\begin{array}{c}\text { Time-Limited } \\
\text { Primary; Never } \\
\text { Subspecialty } \\
\text { Certified } \\
\end{array}$ \\
\hline No. & 1184 & 593 & 418 & 1984 & 483 \\
\hline \multicolumn{6}{|l|}{ Academic practice status } \\
\hline Academic & $29.2 \%$ & $14.0 \%$ & $10.0 \%$ & $30.5 \%$ & $19.3 \%$ \\
\hline Nonacademic & $70.8 \%$ & $86.0 \%$ & $90.0 \%$ & $69.5 \%$ & $80.7 \%$ \\
\hline \multicolumn{6}{|l|}{ Group practice size } \\
\hline$<10$ & $14.0 \%$ & $27.7 \%$ & $25.8 \%$ & $7.0 \%$ & $14.3 \%$ \\
\hline $10-49$ & $31.9 \%$ & $36.8 \%$ & $33.3 \%$ & $32.0 \%$ & $26.9 \%$ \\
\hline $50-99$ & $13.5 \%$ & $9.9 \%$ & $14.4 \%$ & $15.0 \%$ & $13.3 \%$ \\
\hline$\geq 100$ & $40.5 \%$ & $25.6 \%$ & $26.6 \%$ & $46.1 \%$ & $45.5 \%$ \\
\hline \multicolumn{6}{|l|}{ Region } \\
\hline Midwest & $22.3 \%$ & $17.7 \%$ & $17.0 \%$ & $22.8 \%$ & $19.9 \%$ \\
\hline Northeast & $25.3 \%$ & $21.6 \%$ & $21.8 \%$ & $23.3 \%$ & $18.0 \%$ \\
\hline South & $34.1 \%$ & $37.9 \%$ & $31.6 \%$ & $29.5 \%$ & $30.4 \%$ \\
\hline West & $18.3 \%$ & $22.8 \%$ & $29.7 \%$ & $24.4 \%$ & $31.7 \%$ \\
\hline \multicolumn{6}{|l|}{ Years in practice } \\
\hline$\leq 10$ & $0.0 \%$ & $0.0 \%$ & $0.0 \%$ & $11.7 \%$ & $18.7 \%$ \\
\hline $11-20$ & $0.1 \%$ & $0.8 \%$ & $0.0 \%$ & $67.3 \%$ & $58.8 \%$ \\
\hline $21-30$ & $43.3 \%$ & $24.1 \%$ & $41.8 \%$ & $16.8 \%$ & $19.8 \%$ \\
\hline $31-40$ & $46.5 \%$ & $53.9 \%$ & $41.8 \%$ & $4.1 \%$ & $2.4 \%$ \\
\hline $41-50$ & $9.1 \%$ & $17.6 \%$ & $13.5 \%$ & $0.2 \%$ & $0.2 \%$ \\
\hline$\geq 51$ & $1.1 \%$ & $3.7 \%$ & $3.0 \%$ & $0.0 \%$ & $0.0 \%$ \\
\hline
\end{tabular}

${ }^{a}$ Cells in columns for given characteristic add up to 100\%. Columns 1 and 4 in this table together reflect column 1 in Table 2; columns 3 and 5 in this table together reflect column 3 in Table 2 . Column 2 in this table is a subset of column 2 in Table 2. 
Table 4: Distribution of neuroradiology subspecialty certification statuses among majority-practice neuroradiologists with varying characteristics ${ }^{a}$

\begin{tabular}{|c|c|c|c|c|}
\hline & No. & $\begin{array}{c}\text { Currently } \\
\text { Subspecialty } \\
\text { Certified }\end{array}$ & $\begin{array}{l}\text { Previously } \\
\text { Subspecialty } \\
\text { Certified }\end{array}$ & $\begin{array}{c}\text { Never } \\
\text { Subspecialty } \\
\text { Certified }\end{array}$ \\
\hline \multicolumn{5}{|l|}{ Academic status } \\
\hline Nonacademic & 1364 & $58.2 \%$ & $9.1 \%$ & $32.7 \%$ \\
\hline Academic & 811 & $81.3 \%$ & $5.1 \%$ & $13.5 \%$ \\
\hline \multicolumn{5}{|c|}{ Group practice size } \\
\hline$<10$ & 132 & $36.1 \%$ & $15.6 \%$ & $48.4 \%$ \\
\hline $10-49$ & 623 & $63.2 \%$ & $9.5 \%$ & $27.3 \%$ \\
\hline $50-99$ & 356 & $69.4 \%$ & $6.4 \%$ & $24.2 \%$ \\
\hline$\geq 100$ & 1064 & $72.1 \%$ & $5.5 \%$ & $22.4 \%$ \\
\hline \multicolumn{5}{|c|}{ Geographic region } \\
\hline Midwest & 505 & $70.6 \%$ & $6.0 \%$ & $23.4 \%$ \\
\hline Northeast & 563 & $69.8 \%$ & $8.2 \%$ & $22.1 \%$ \\
\hline South & 674 & $64.1 \%$ & $9.4 \%$ & $26.5 \%$ \\
\hline West & 433 & $56.5 \%$ & $7.4 \%$ & $36.1 \%$ \\
\hline \multicolumn{5}{|l|}{ Years in practice } \\
\hline$\leq 10$ & 149 & $63.4 \%$ & $0.0 \%$ & $36.6 \%$ \\
\hline $11-20$ & 936 & $77.5 \%$ & $0.1 \%$ & $22.4 \%$ \\
\hline $21-30$ & 544 & $65.0 \%$ & $6.0 \%$ & $29.0 \%$ \\
\hline $31-40$ & 414 & $59.1 \%$ & $17.6 \%$ & $23.3 \%$ \\
\hline $41-50$ & 73 & $43.7 \%$ & $26.3 \%$ & $29.9 \%$ \\
\hline$\geq 51$ & 10 & $31.3 \%$ & $34.4 \%$ & $34.4 \%$ \\
\hline \multicolumn{5}{|c|}{ Primary certificate } \\
\hline Lifetime & 828 & $54.9 \%$ & $17.4 \%$ & $27.7 \%$ \\
\hline Time-limited & 1347 & $73.5 \%$ & $0.1 \%$ & $26.4 \%$ \\
\hline
\end{tabular}

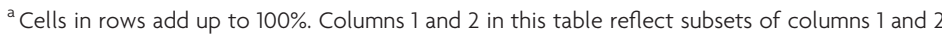
in Table 2; column 3 in this table reflects the same neuroradiologists as in column 3 of Table 2.

Table 5: Results of multivariable regression analysis for identifying factors associated with current subspecialty certification among radiologists with a majority-neuroradiology practice

\begin{tabular}{llccc}
\hline \multicolumn{1}{c}{ Reference } & \multicolumn{1}{c}{ Criterion } & Odds Ratio & 95\% Cl & \multicolumn{1}{c}{$\boldsymbol{P}$} \\
\hline Nonacademic & Academic & 2.82 & $2.27-3.50$ & $<.001$ \\
$<10$ Members & 10-49 members & 2.03 & $1.48-2.80$ & $<.001$ \\
$<10$ Members & 50-99 members & 2.51 & $1.77-3.55$ & $<.001$ \\
$<10$ Members & 100+ members & 1.94 & $1.40-2.70$ & $<.001$ \\
West & Midwest & 1.65 & $1.30-2.09$ & $<.001$ \\
West & Northeast & 1.63 & $1.29-2.06$ & .022 \\
West & South & 1.45 & $1.18-1.80$ & $<.001$ \\
$\geq 51 \mathrm{yr}$ & $\leq 10 \mathrm{yr}$ & 2.81 & $1.16-6.81$ & $<.001$ \\
$\geq 51 \mathrm{yr}$ & $11-20 \mathrm{yr}$ & 6.12 & $2.61-14.38$ & $<.001$ \\
$\geq 51 \mathrm{yr}$ & $21-30 \mathrm{yr}$ & 4.08 & $1.81-9.20$ & $<.001$ \\
$\geq 51 \mathrm{yr}$ & $31-40 \mathrm{yr}$ & 3.44 & $1.53-7.72$ & .003 \\
$\geq 51 \mathrm{yr}$ & $41-50 \mathrm{yr}$ & 1.72 & $0.73-4.02$ & .214 \\
Lifetime primary & Time-limited primary & 1.41 & $1.06-1.88$ & .017 \\
\hline
\end{tabular}

subspecialty certified, $52.2 \%$ for those previously subspecialty certified, and $72.4 \%$ for those never subspecialty certified with majority-neuroradiology practices. The fraction in academic practice was $30.0 \%$ for those currently subspecialty certified, $14.1 \%$ for those previously subspecialty certified, and $15.0 \%$ for those never subspecialty certified with majority-neuroradiology practices. The fraction with lifetime primary certificates was $37.4 \%$ among those currently subspecialty certified, $98.7 \%$ among those previously subspecialty certified, and $46.4 \%$ among those never subspecialty certified with majority-neuroradiology practices.

Table 3 summarizes these same characteristics based on 5 different nonoverlapping combinations of primary certificate status and neuroradiology subspecialty certification status. Mean neuroradiology work effort varied from $52.4 \%$ to $73.2 \%$ across these groups. For lifetime primary certificate holders, the fractions in an academic practice were the following: $29.2 \%$ for those currently subspecialty certified, $14.0 \%$ for those previously subspecialty certified, and $10.0 \%$ for those never subspecialty certified. For time-limited primary certificate holders, the fractions in an academic practice were $30.5 \%$ for those currently subspecialty certified and $19.3 \%$ for those previously subspecialty certified.

Among 3341 radiologists with majority-neuroradiology practices (Table 4), the fraction currently subspecialty certified was higher for those in academic (81.3\%) versus nonacademic (58.2\%) practices, largerversus-smaller practices $(72.1 \%$ for those in $\geq 100$ versus $36.1 \%$ for $<10$-member practices), US regions other than the West (64.1\%-70.6\% versus $56.5 \%)$, with fewer years in practice $(77.5 \%$ for $11-20$ years versus $31.3 \%$ for $>50$ years), and time-limited $(73.5 \%)$ versus lifetime (54.9\%) primary certificates.

At multivariable regression among radiologists with a majority-neuroradiology practice (Table 5), all of the included physician and practice characteristics were significant independent predictors of being currently subspecialty certified. The strongest such predictors were earlier career stage (odds ratio $=6.12$ for 11 20 years in practice relative to $\geq 51$ years in practice) and academic practice status (odds ratio $=2.82$ relative to nonacademic practice status). The Figure demonstrates the state-level percentage of majority-practice neuroradiologists currently subspecialty certified. The fraction was highest $(\geq 80 \%)$ in South Dakota, Vermont, and Idaho and lowest $(\leq 20 \%)$ in North Dakota, Wyoming, and Alaska.

\section{DISCUSSION}

Identifying radiologists by linking $\mathrm{ABR}$ search engine data to 2 different CMS datasets, we characterized subspecialty-certification characteristics of neuroradiologists and observed that more than one-quarter of radiologists with a majority-neuroradiology practice had never obtained subspecialty certification. Numerous physician and practice characteristics were associated with the likelihood of doing so. Across numerous analyses, attaining neuroradiology subspecialty certification was substantially more common among academic radiologists. The reasons for the lack of such certification among neuroradiologists in nonacademic practices are unknown, but on the basis of our data, warrant further investigation.

Among the requirements for seeking subspecialty certification, completing a neuroradiology fellowship and having additional practice experience in the subspecialty would not seem to pose a challenge from a practical standpoint. However, a barrier or disincentive to some majority-neuroradiology practice radiologists may be the additional certification examination. This examination entails additional test preparation, additional time away from work to travel to the examination center (currently 


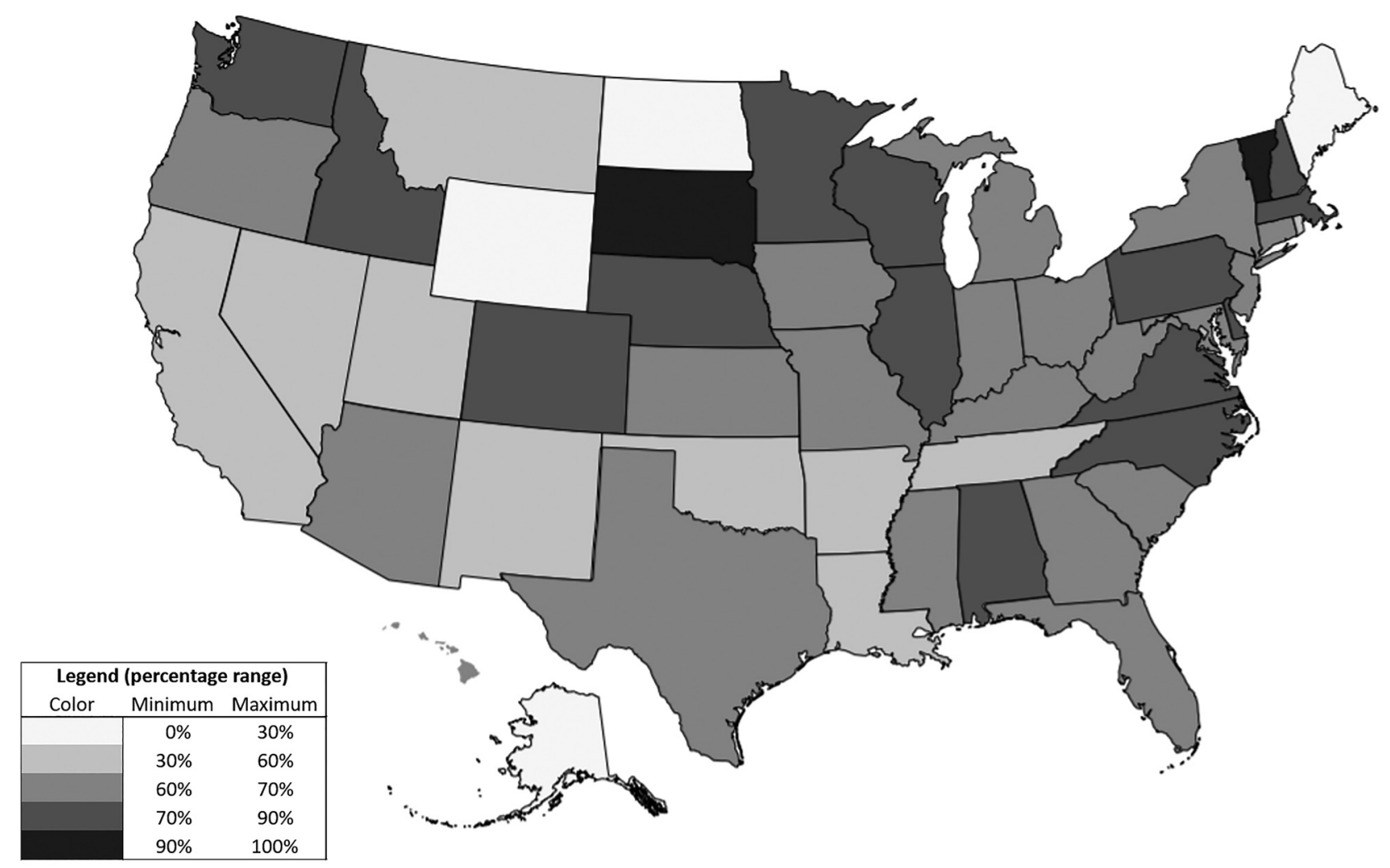

FIGURE. State-level variation among radiologists with a majority-neuroradiology practice in terms of being currently subspecialty certified. The intermediate shade corresponds with a percentage within a $60 \%-70 \%$ range, approaching the overall national rate of $65 \%$. Lighter shades correspond with a rate under $60 \%$, and darker shades correspond with a rate of at least $70 \%$.

offered on only 2 dates in the year and in only 2 different US cities), ${ }^{8}$ an additional examination fee, as well as the stress of the examination itself. A neuroradiologist might be motivated to undertake this process if perceiving some tangible benefit from achieving that additional certificate. However, subspecialty certification is generally not needed from a credentialing standpoint or for other reasons to practice within the discipline. It is possible that individual diplomates are internally motivated to seek additional certification due to a sense of fulfillment or accomplishment through the formal recognition by the ABR. Individuals may also be motivated by external factors such as a desire to be more competitive when seeking employment; to fulfill an expectation if attaining employment in a group in which the certification is the norm among the group's neuroradiologists; or, even if working in a group where it is not the norm, to, nonetheless, attain prestige, respect, or standing within one's group. Individuals may also pursue certification to enhance their public reputation, given that the public can readily identify whether a neuroradiologist has subspecialty certification through the certificate verification public search engine of the ABR. ${ }^{16}$ Some of these factors, such as prestige or fitting the norm or group expectation, may be more relevant for academic practices.

Some of the other factors we identified associated with subspecialty certification are expected. Subspecialty certification was more common for radiologists in larger practices, which themselves may be more academic and more subspecialized. In addition, subspecialty certification was more common for earlier career radiologists. This is also not unexpected because neuroradiology subspecialty certification was only first offered in 1995 so that it was not available at the time that more senior radiologists were completing training and beginning their careers (ie, the stage when radiologists are more likely to undergo testing and pursue certification). According to 1 report, the number of registrants for the neuroradiology subspecialty certification examination increased from approximately 80 from 2003-2005 to 134 in 2006, and 160 in 2007, supporting a gradual rise in the subspecialty certification since first being introduced. ${ }^{1}$ Most interesting, certification rates were least common in the Western United States and were not consistently high or low in either large or small states or in neighboring states, indicating possible regional cultural influences on seeking certification. Targeted survey-based studies could complement our present analysis to better understand neuroradiologists' motivations for seeking (or not seeking) subspecialty certification but would operationally require email contact information not made publicly available by the ABR or CMS.

Overall, staying currently subspecialty-certified was very common for those with time-limited primary certificates (ie, MOC already required for the primary certificate), which would be expected given that the ABR has integrated its MOC programs for primary and secondary certificates-that is, diplomates fulfill the MOC requirements of both certificates 
without having to answer any additional test questions or pay any additional fees beyond that for their primary certificates. In this regard, there are currently larger barriers to initially attaining, rather than to subsequently maintaining, subspecialty certification.

In comparison, approximately a third of neuroradiologists with lifetime primary certificates (ie, MOC not required for their primary certificates) and who had, at some point, obtained subspecialty certification were no longer currently subspecialty certified. These rates were particularly low for lifetime certificate holders in nonacademic and smaller practices. The underlying factors behind the lack of MOC participation in these groups may be similar to those influencing these radiologists' lower rates of attaining subspecialty certification in the first place. A national survey in 2008 observed high rates of misunderstanding regarding the MOC by neuroradiologists, as well as unfavorable views of the MOC relating to inconvenience and cost, contributing to resistance and noncompliance. ${ }^{17}$ While the ABR has taken steps to simplify its MOC process through the introduction of its Online Longitudinal Assessment initiative, ${ }^{18}$ lingering misconceptions and negative perspectives could continue to influence decisions regarding voluntary MOC. In this regard, our present study provides a baseline assessment; further longitudinal investigations would be necessary to determine how and if the Online Longitudinal Assessment initiative might be more widely accepted.

ABR leadership has indicated that the advent of neuroradiology subspecialty certification has elevated the level of neuroradiology practice nationally. ${ }^{1,2}$ If this is indeed the case, professional thought leaders need a better understanding of neuroradiologists' motivations to attain certification. This, in turn, may be facilitated by insight into which neuroradiologists are-versus-are not participating, for which our analysis provides concrete data. It has also been proposed that national specialty societies such as the American Society of Neuroradiology should play a leading role in educating neuroradiologists and providing resources to encourage subspecialty certification participation. ${ }^{17}$ Ultimately, to be successful in incentivizing greater participation, proponents of certification will need to make a compelling case for the value added to their intended audiences.

This study has several limitations. First, given the public availability from CMS of claims resources to identify actively practicing radiologists, we only included neuroradiologists participating in the Medicare program. Pediatric neuroradiologists may thus be underrepresented. In addition, the ABR has, in recent years, changed aspects of its program for primary certificate initial certification, primary certification maintenance, subspecialty certificate initial certification, and subspecialty certificate maintenance. Thus, board participation characteristics may remain a moving target that can be difficult to precisely quantify, given that available data reflect a conglomerate of physicians' behavior across different ABR certification policies. Also, it is possible that some radiologists with a majority-neuroradiology practice did not seek subspecialty certification due to never having completed a neuroradiology fellowship (thus making them ineligible for the certification through the standard pathway). However, we are unaware of any publicly available dataset listing radiologists' fellowships. Furthermore, while the ABR provides an alternate pathway to subspecialty certification for those who did not complete an accredited fellowship, ${ }^{19}$ the ABR public search engine does not indicate whether subspecialty diplomates followed the standard or alternate pathway, precluding inclusion of this factor in our investigation. Finally, because this study was focused entirely on neuroradiology subspecialty certification, it is not clear whether the observed patterns apply, in a similar fashion, to other ABR radiology subspecialty certificates (eg, nuclear radiology and pediatric radiology).

\section{CONCLUSIONS}

More than one-quarter of radiologists with a majorityneuroradiology practice have never obtained neuroradiology subspecialty certification. Even when initially obtained, that certification is commonly not maintained, particularly among lifetime primary certificate diplomates. Neuroradiologists in nonacademic practices were less likely to both initially attain and subsequently maintain neuroradiology subspecialty certification. Further investigation is warranted to better understand such decisions by neuroradiologists regarding subspecialty certification participation.

Disclosures: Andrew B. Rosenkrantz-RELATED: Grant: Harvey L. Neiman Health Policy Institute.* Richard Duszak-RELATED: Grant: Harvey L. Neiman Health Policy Institute.* *Money paid to the institution.

\section{REFERENCES}

1. Forbes GS, Yock DH. Maintaining subspecialty certification in neuroradiology. AJNR Am J Neuroradiol 2008;29:228 CrossRef Medline

2. Lukin RR, Forbes GS. Why I should take my CAQ recertification examination. AJNR Am J Neuroradiol 2004;25:668-69

3. American Board of Radiology. Neuroradiology. https://www.theabr. org/diagnostic-radiology/subspecialties/neuroradiology. Accessed June 27, 2019

4. Hirsch JA, Becker GJ, Derdeyn CP, et al. Maintenance of certification: Part 2, continuous certification. J Neurointerv Surg 2014; 6:156-60 CrossRef Medline

5. Hirsch JA, Meyers PM. Maintenance of certification: historical context. J Neurointervent Surg 2013;5:612-14 CrossRef Medline

6. Zimmerman R. Changing Structure of the ABR Exams and the Effect on Neuroradiology. AJNR Blog. http://www.ajnrblog.org/ 2009/10/27/changing-structure-of-the-abr-exams-and-the-effect-onneuroradiology/. Published on October 27, 2009. Accessed June 27, 2019

7. American Board of Radiology. Requirements and Registration. https://www.theabr.org/diagnostic-radiology/subspecialties/ neuroradiology/requirements-registration. Accessed June 27, 2019

8. American Board of Radiology. Dates, Locations, Fees. https://www. theabr.org/diagnostic-radiology/subspecialties/neuroradiology/dateslocations-fees. Accessed June 27, 2019

9. American Board of Radiology. Maintenance of Certification for Diagnostic Radiology. https://www.theabr.org/diagnostic-radiology/ maintenance-of-certification. Accessed June 27, 2019

10. Rosenkrantz AB, Berland LL, Heitkamp DE, et al. Diagnostic radiologists' participation in the American Board of Radiology's 
maintenance of certification program. AJR Am J Roentgenol. 2019;213

11. Rosenkrantz AB, Wang W, Hughes DR, et al. Academic radiologist subspecialty identification using a novel claims-based classification system. AJR Am J Roentgenol 2017;208:1249-55 CrossRef Medline

12. > Rosenkrantz AB, Wang W, Bodapati S, et al. Private practice radiologist subspecialty classification using medicare claims. J Am Coll Radiology 2017;14:1419-25 CrossRef Medline

13. Rosenkrantz AB, Wang W, Hughes DR, et al. Generalist versus subspecialist characteristics of the U.S. radiologist workforce. Radiology 2018;286:929-37 CrossRef Medline

14. Centers for Medicare \& Medicaid Services. Physician Compare data sets; downloadable file. https://data.medicare.gov/data/physiciancompare. Accessed February 26, 2019
15. Harvey L. Neiman Health Policy Institute. Identification of Academic Radiology Practices. http://www.neimanhpi.org/academicradiology-practices/. Accessed October 13, 2018

16. American Board of Radiology. Verify Board Certification Status. https:// www.theabr.org/myabr/find-a-radiologist. Accessed January 8, 2019

17. Yousem DM. Maintenance of certification: current attitudes of members of the American Society of Neuroradiology. AJNR Am J Neuroradiol 2008;29:224-27 CrossRef Medline

18. American Board of Radiology. Online Longitudinal Assessment (OLA). https://www.theabr.org/online-longitudinal-assessment-ola. Accessed March 19, 2019

19. American Board of Radiology. Alternate Pathway to Subspecialty Certification. https://www.theabr.org/diagnostic-radiology/subspecialties/ neuroradiology/alternate-pathway. Accessed August 5, 2019 